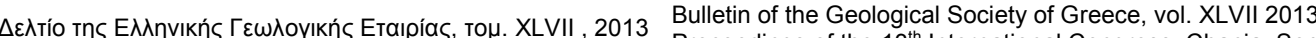
Proceedings of the $13^{\text {th }}$ International Congress, Chania Sept.

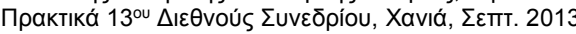
2013

\title{
DELINEATION OF RECHARGE AREAS OF THE AQUIFER SYSTEMS OF CORINTHIA PREFECTURE BY THE USE OF ISOTOPIC EVIDENCE
}

\author{
Antonakos A. ${ }^{1}$ and Nikas K. ${ }^{2}$ \\ IGeneral Secretariat for Civil Protection,Evagelistrias 2, 105 63, Athens, aantonako@yahoo.gr \\ ${ }^{2}$ IGME. $1^{\text {st }}$ Spirou Louis St., Olympic Village, 13677 Acharnae.nikas1kostas@gmail.com
}

\begin{abstract}
The results of a ground water isotopic research program conducted during the period 2004-2008 by an IGME/Hydrogeology Department team in the area of North Korinthian prefecture are presented here. 69 ground water samples were collected during the period 6/2007 and analyzed in the laboratory of Isotope Hydrology of NCSR "Demokritos" for Oxygen isotopes $\delta^{18} O$ and Tritium. From the spatial distribution of $\delta^{18} \mathrm{O}$, the conglomerate aquifer systems seem to be recharging from their outcrop areas and possibly laterally from the karstic systems that outcrops in higher altitudes. The rest aquifer systems of the area seem to be recharging exclusively from their outcrop areas with the exception of the Vocha coastal alluvial aquifer which seem to be recharging almost totally from waters coming from higher altitudes. According to the spatial distribution of Tritium in both Sikion-Velo and VrachatiLechaio areas, low Tritium values are observed which are indicative of the fact that the aquifer system of those areas are recharged from vertical seepage from the riverbeds of Asopos and Rachiani rivers respectively. Contrariwise in the area of Krines-Zevgolatio the high values of Tritium reveal the lateral recharge from the adjacent marine terraces and marl aquifers.
\end{abstract}

Key words: $\delta^{18} O$, Tritium, aquifer, lateral recharge.

\section{Пєрí $\eta \psi \eta$}

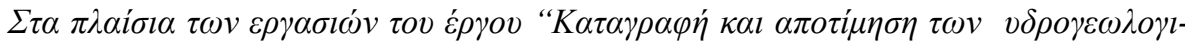

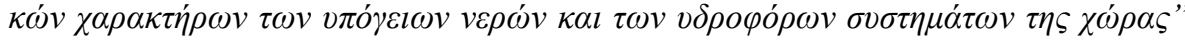

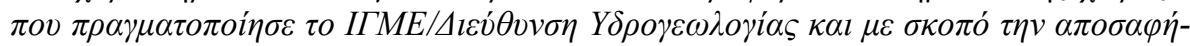

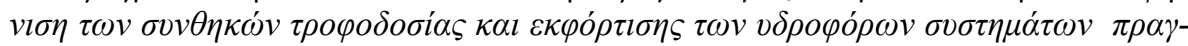

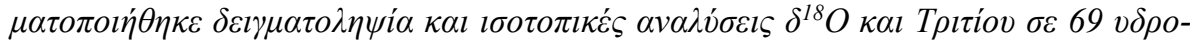

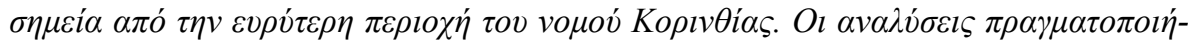

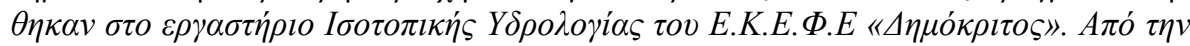

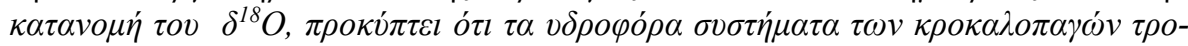

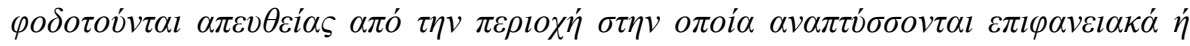

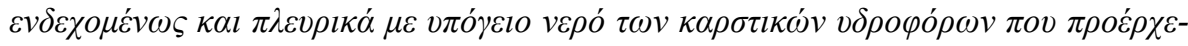

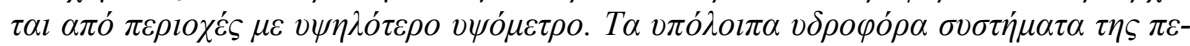

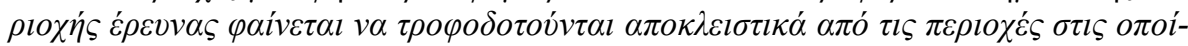

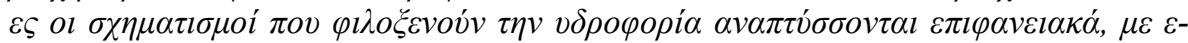

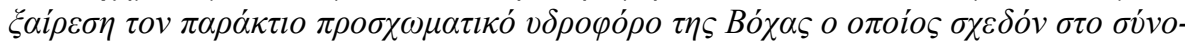

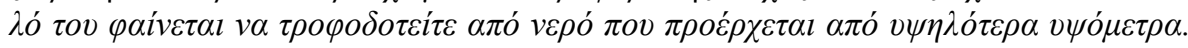

XLVII. No $2-692$ 


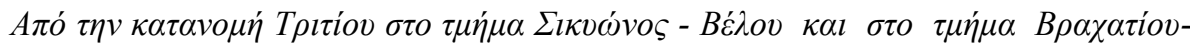

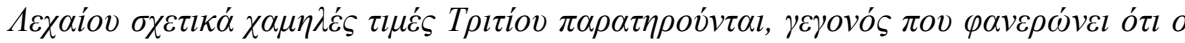

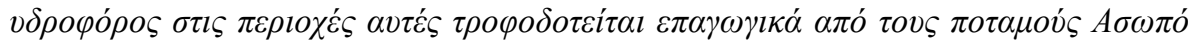

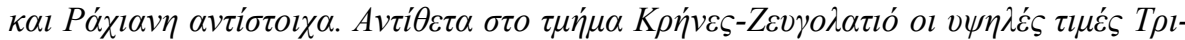

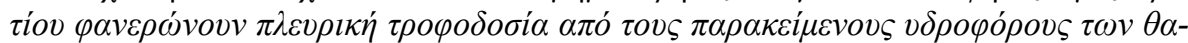
$\lambda \alpha \dot{\sigma \sigma} \sigma \omega v \alpha v \alpha \beta \alpha \theta \mu i \delta \omega v \kappa \alpha l \tau \omega v \mu \alpha \rho \gamma \omega ́ v$.

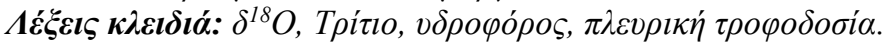

\section{Introduction}

As part of the project No 12 "Study of Water Resources of North Peloponnese Water District, with Emphasis on Quality Characteristics and Seawater Intrusion Phenomena" (Nikas and Antonakos, 2010) which respectively was part of the broader project "Inventory and valuation of the hydrogeologic character of groundwater and aquifer systems in the Hellenic country", funded by the $3^{\text {rd }}$ EU Framework budget and in order to fully assess the hydrochemical conditions and clarify the conditions of the aquifer recharge and discharge, groundwater isotopic analyses were conducted for a series of samples collected from the area of Korinthia prefecture.

\section{Geological and Hydrogeological Setting}

The study area is located in the northeastern part of Peloponnesus Greece, in the central part of Korinthia prefecture area and it is approximately $902 \mathrm{Km}^{2}$ in area (Figure 1). The geological bedrock consists of the carbonate sediments of the Trapezona sequence (a transition zone between Pindos and Pelagonian geotectonic zones) in the southeastern part of the study area and the carbonate sediments and flysch of the Pindos and Tripolis zones in the southwestern part of the study area (Katsikatsos, 1992).

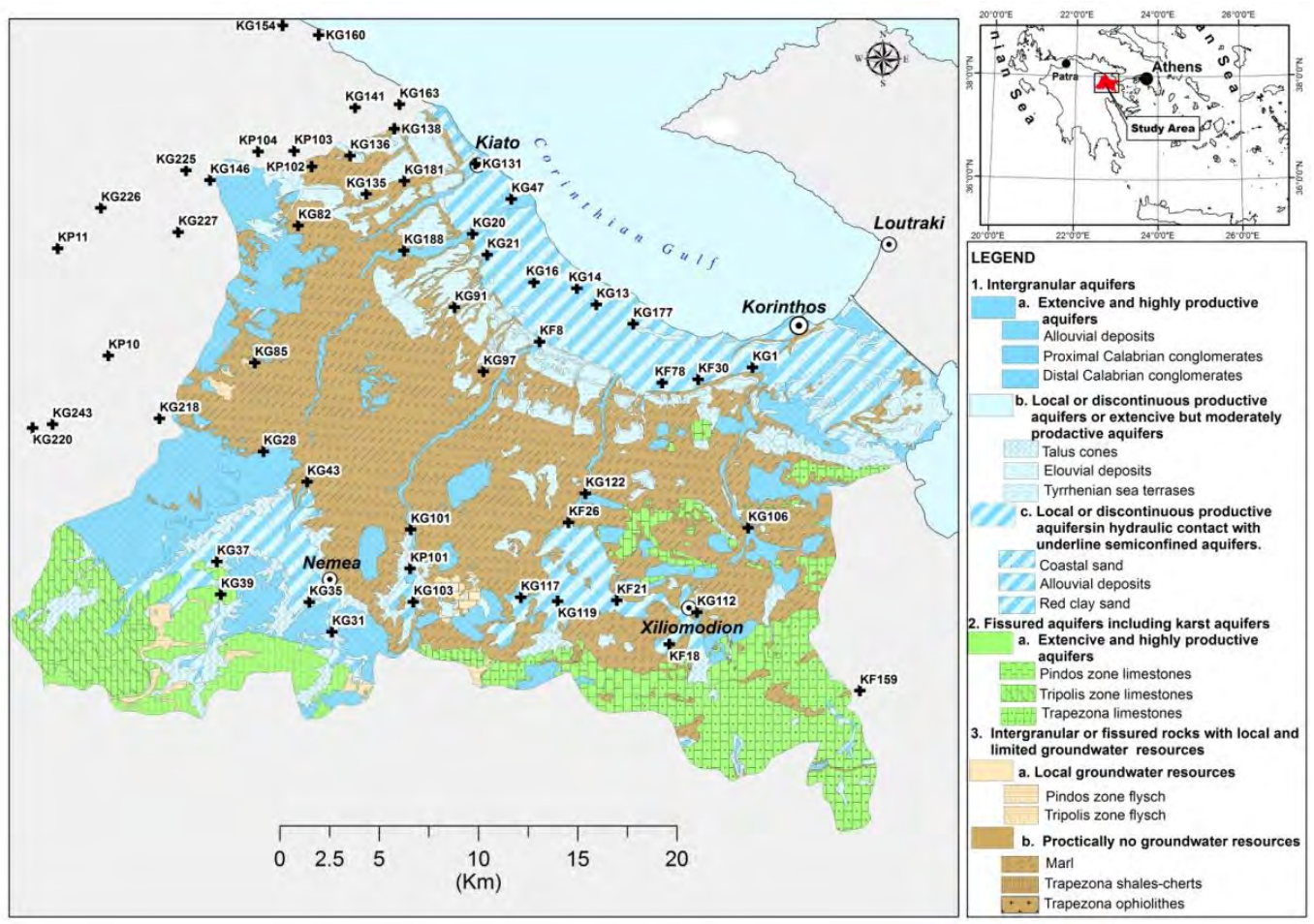

Figure 1 - Hydrogeological map of the study area with the location of the sampling points.

XLVII. No 2-693 
The Trapezona carbonate sequence consists of plated limestones of Triassic to Upper Jurassic age with nodules and thin bands of chert. In Middle Jurassic, this sequence was intermingled and interbedded with the shale-chert formation made up of bedded sandstone, clay and marl with ophiolithic bodies.

The Tripolis zone consists mostly of the dolomitic limestone of the limestone series of Upper Jurassic to Eocene age which is unconformably overlaid by the Tripolis zone flysch formation.

The Pindos zone formation in the study area consists of Upper Cretaceous platy limestones which are unconformably overlaid by the flysch formation. Pindos zone is geotectonically overthrusted on the Tripolis zone with a general NE-SW thrust direction.

The main part of the study area is covered by post orogenic sediments of Pliocene to Holocene age which uncomformably overlay the bedrock formations. They consist of Pliocene lacustrine marls interbedded by thin layers of conglomerates and sandstones, fluvial (proximal and distal) cemented conglomerates of Calabrian age, sea terraces of Tyrinian age, eluvial deposits consisting of alterations of red sand, clay, sandy loam and loose conglomerates of Pleistocene age and finally recent alluvial deposits and talus cones.

From the hydrogeological point of view six major hydrogeological units (aquifers and aquitards) can be distinguished (Antonakos and Lambrakis, 2007) according to the classification proposed by IAH and implemented thereafter in the International Hydrogelogical Map of Europe (Nikas et al., 2010):

- The carbonate aquifers of the bedrock system which are fully karstic for the Trapezona sequence and Tripolis zone and partly karstic for the Pindos zone. They are highly productive aquifers with an average thickness of 100 to $400 \mathrm{~m}$ and hydraulic conductivity values ranging from 0.34 to $775.6 \mathrm{~m}$ /day (Nikas et al., 2008).

- The flysch formations of Tripolis and Pindos zones and the shale-chert formations of the Trapezona sequence which can be distinguished here as the confining (impermeable) units in the whole aquifer system.

- The Pliocene marl aquifer that develops almost exclusively in the thin beds of sandstones and conglomerates which are found here interbedded within the whole marl formation. It is a confined type of aquifer with an average thickness of 2-10 $\mathrm{m}$ and generally low hydraulic conductivity values $(0.086 \mathrm{~m} /$ day $)$.

- The Calabrian conglomerates aquifer with an average thickness of 50-100 $\mathrm{m}$ and high values of hydraulic conductivity (129.6 m/day).

- The aquifer that develops within the eluvial and sea terraces formations, with an average thickness of $30-50 \mathrm{~m}$ and medium to high hydraulic conductivity values $(1.72 \mathrm{~m} /$ day $)$ (Voudouris et al., 2000).

- The aquifer that develops within the recent alluvial and talus cone deposits with an average thickness of 40-60 m and hydraulic conductivity values ranging from 8.64 to $69.12 \mathrm{~m} /$ day. This aquifer is, in the most of the cases, in hydraulic contact with the adjacent or underlying aquifer of eluvial and sea terraces formations and is laterally recharged from them.

The impermeable stratum that underlies all the aquifers of the post orogenic sediments is in general the lacustrine marls of the Pliocene marl formation.

The mean annual precipitation in the study area is $594 \mathrm{~mm}$ which in quantitative terms corresponds to mean annual rainfall water volume of $536.5^{*} 10^{6} \mathrm{~m}^{3}$. The water balance parameters have been computed based on the procedures described by Thornthwaite and Mather (1955). An amount $67.5 \%$ of the annual precipitation, namely $360.9^{*} 10^{6} \mathrm{~m}^{3}$, is lost via the process of evapotranspiration while $19.1 \%$, namely $102.6^{*} 10^{6} \mathrm{~m}^{3}$, infiltrates and recharges the groundwater 
system. The rest $13.4 \%$, namely $71.8 * 10^{6} \mathrm{~m}^{3}$, discharges to the sea as surface runoff (Voudouris et al., 2007).

A major part of the study area, namely $49.9 \%$, is covered with intensive cultivations (vineyards, fruit trees, olive groves) which are widely spread in the whole extent of the study area. The use of inorganic fertilizers in these cultivations has a great polluting effect on groundwater. The composition of these fertilizers is mainly ammonium sulfate and ammonium nitrate so the major expected pollutant in the study area is nitrogen mainly in the form of nitrates. A big part of the coastal zone of the study area is covered by urban and suburban areas which add an extra environmental pressure to the groundwater of the costal alluvial aquifer system.

\section{Materials and Methods}

\subsection{Research Framework}

Analyses were performed in the laboratory of Isotope Hydrology of NCSR "Demokritos". More specifically, sampling of groundwater was conducted from 69 sample points during the period $6 / 2007$ and isotopic analyzes were carried out afterwards for the determination of $\delta^{18} O$ and Tritium concentration. The method used for the analysis of stable isotopes was the Isotope Ratio Mass Spectrometry (IRMS). The measurement accuracy was $\pm 0.22 \%$ for the value of $\delta^{18} \mathrm{O}$ and \pm 0.51 $\%$ for the value of $\delta^{2} \mathrm{H}$.

\subsection{Isotopic Hydrology Basic Principles}

The Isotopic hydrology is a field of hydrology that uses isotopic dating to estimate the age and ori gins of water and of movement within the hydrologic cycle. It evolves the behavioral examination of stable $\left({ }^{18} \mathrm{O},{ }^{2} \mathrm{H},{ }^{13} \mathrm{C}\right)$ and radioactive $\left({ }^{14} \mathrm{C},{ }^{3} \mathrm{H}\right)$ isotopes, during the water cycle.

More specifically, with Isotope Hydrology the altitude of the recharge area of an aquifer can be det ermined, as well as, the mixing between different types of groundwater, the degree of mixing of su rface and groundwater, the rate of evaporation, the inflow and outflow of surface water systems, th e groundwater salination and the groundwater residence time in aquifers (Matiatos et al., 2010).

As isotopic ratio, $R$, of an isotope in a water sample, the ratio of the number of atoms of the isotop $\mathrm{e}$ in the sample to the total number of atoms of the same element in the sample, is defined:

\section{Equation 1 - Isotopic Ratio}

$$
R=\frac{\text { number of atoms of the isotope }}{\text { number of atoms of the element }}
$$

As "isotopic fractionation" the modification of an isotopic ratio (e.g., ${ }^{18} \mathrm{O} /{ }^{16} \mathrm{O}$ ) during the transition of the molecules of a compound from one phase to another or during the transition of a chemical reaction, is defined. When a process does not attain isotopic fractionation, it is said that the isotopes involved in this process are in isotopic equilibrium.

Because the three isotopic species of water have different molecular mass, they exhibit also differences in their physicochemical properties (e.g. lighter molecules of $\mathrm{H}_{2}{ }^{16} \mathrm{O}$ which can evaporate more easily than the heavier $\mathrm{H}_{2}{ }^{18} \mathrm{O}$ ). Thus, during the various stages of the water cycle (evaporation, condensation), a part of the environment is enriched in one isotopic species, while another becomes poorer. There is, therefore, a change in the isotopic ratio and that is called "isotopic fractionation» (Kendall and Caldwell, 1998).

Due to the importance of the behavior of the ${ }^{18} \mathrm{O} /{ }^{16} \mathrm{O}$ ratio, another example of Oxygen isotopic fractionation within the water cycle is mentioned hereafter. During the evaporation of ocean water, the steam that arises is poorer in heavy isotopes $\left({ }^{18} \mathrm{O},{ }^{2} \mathrm{H}\right)$. When the uplifting steam encounters the cold layers of air it forms a condensate (cloud) which is richer than the original uplifting steam in heavy isotopes. The steam that remains is thus poorer in isotopes than the original. The water 
falling as rain is more concentrated, while the remaining steam is further moved towards the interior of continents, where it meets new coldest areas resulting in new compression and further reduction in its content in heavy isotopes.

The decreasing of the content of a steam in heavy isotopes is more intense, as the condensation temperature is less. So rain falling in coastal areas has almost the same isotopic composition as seawater where, in contrast, rainwater falling on the mainland is generally poorer in both heavy isotopes, the rate of difference being increasing as the distance from the sea gets greater. In general, the rainwater that falls on the highlands occurs more depleted in heavy isotopes than the rainwater that falls on coastal plains (Kalergis and Leontiadis, 1983).

In this context, the high precision of the measurements of mass spectrometry allows us to differentiate between rainwater that comes from areas with difference in altitude, within a range of 200 meters.

Isotopic fractionation occurs, as already mentioned also during chemical reactions (e.g. when groundwater reacts with minerals found within the aquifer system).

To quantify the effects of isotopic fractionation, in a reversible chemical reaction or phase change, under equilibrium conditions, in the form $\mathrm{A} \leftrightarrow \mathrm{B}$, the Isotopic Fractionation Ratio or Fractionation Coefficient $\alpha$, is introduced:

\section{Equation 2 - Isotopic Ratio}

$$
a=\frac{R_{i}}{R_{v}}
$$

Where i: the fluid phase and v: the steam phase

Isotopic Fractionation Ratio $\alpha$, depends on the temperature and more specifically it increases when the temperature decreases.

The isotopic ratio cannot be measured accurately because changes can happen even during the measuring process. But with the mass spectrometer measurement the difference of the isotopic ratio of a sample from an acknowledged standard measurement can be measured with great accuracy. The most commonly used standard is the SMOW (Standard Mean Ocean Water) for the isotopes ${ }^{18} \mathrm{O}$ and ${ }^{2} \mathrm{H}$ which approximates the average isotopic composition of the ocean water (International Atomic Energy Agency, 1981).

This difference is denoted by the Greek letter $\delta$, is measured in parts per million and is given by the following equation:

$$
\delta(\%)=\frac{\left(R_{x}-R_{s t}\right)}{R_{s t}} \cdot 1000
$$

Where $R_{x}$ is the isotopic ratio of the sample and $R_{s t}$ is the isotopic ratio of the standard.

If the value of $\delta$ is positive $\left(R_{x}-R_{s t}>1\right)$, then the sample is richer than the standard in heavy isotopes. If the value of $\delta$ is negative $\left(R_{x}-R_{s t}<1\right)$, then the sample is poorer than the standard in heavy isotopes (Kendall et al., 1995).

For example, if we have a water sample with $\delta^{18} \mathrm{O}=-5 \%$, we get the information that the sample has $5 \%{ }^{18} \mathrm{O}$ less than the standard.

The main changes in the isotopic composition of natural waters take place in the atmosphere and in surface waters. Water found in soil and subsoil retains the characteristics of meteoric and surface water infiltrating the ground (unless mixed with other waters of different isotopic origin). 
The International Atomic Energy Agency (IAEA) has done a lot of research on the field of oxygen and hydrogen isotopes in precipitation, since 1961, and has created 144 research centers, many of which are still operative. These centers include islands, coastal and inland areas. The main conclusions of IAEA studies can be summarized as follows (Leontiadis et al., 1996):

- Meteoric waters are poorer in heavy isotopes than seawater.

- The oceans have stable isotopic composition.

- Concentrations of ${ }^{2} \mathrm{H}$ and ${ }^{18} \mathrm{O}$ in seawater vary proportionally.

- The concentration of heavy isotopes in precipitation decreases as the condensing temperature decreases (temperature effect). This general conclusion leads to a series of different effects on isotopic composition of natural waters:

- Reduction of the isotopic composition in precipitation with increasing latitude and altitude (latitude effect, altitude effect),

- Seasonal variation of the isotopic composition in precipitation (seasonal variation),

- Reduction of the isotopic composition with increasing amount of precipitation (amount effect),

- Reduction of the isotopic composition in precipitation with increasing distance from the ocean (continental effect).

- Intense evaporation affects the proportional relationship between values of $\delta^{2} \mathrm{H}$ and $\delta^{18} \mathrm{O}$ (kinetic effect).

Tritium $\left({ }^{3} \mathrm{H}\right)$ is a radioactive isotope of hydrogen with a half-life of 12.26 years. It is produced in the nature in the upper atmosphere, as a result of the influence of cosmic radiation on nitrogen molecules. The tritium produced in this way reacts with oxygen in the air and forms water, which falls to the earth within the whole rainwater volume. The concentration of rainwater in natural tritium is between 6 and 15 units of tritium (one unit is equivalent to a tritium atom every 1018 hydrogen atoms). The balance between the constant rate of production of natural tritium, constant rate of decay and the various changes in the water cycle in nature was disrupted by thermonuclear tests in the atmosphere. Large quantities of tritium were then passed in the troposphere, from where they still return to the atmosphere (Christodoulou et al., 1993).

Systematic measurements of the tritium content of rainwater started since 1961 in a number of stations established around the world. The tritium concentration in rain water reached about 6000 tritium units (TU) in 1963 and then decreased, but is still at a higher level than it used to be in the period before 1952 .

In areas of similar latitude, a satisfactory correspondence in the value of mean concentration of tritium in rainwater is observed. Nevertheless, regardless of the latitude, the various regions may be classified into groups, which are affected only by air masses of the same origin and in which therefore, the tritium isolines are presented parallel. Thus, it is possible and with reasonable accuracy, the reference to the history of tritium for a particular area, being afterwards presented, by correlating that area with another typical area.

When an amount of water is exposed to the ground surface, equilibrium appeared between the rate of atmosphere uptake and the rate of tritium loss: the latter being occurred as a result either to tritium reactions or from other unidentified causes. On the other hand it is obvious that when water isolates itself from the atmosphere, the concentration of tritium found in these waters also decreases, according to the known laws of radioactive isotopes decay. By measuring therefore the amount of reduction, it is possible to calculate the elapsed time since the water was isolated from the atmosphere. Because, and as a consequence of thermonuclear tests, the tritium concentration in rainwater has not been stable in the past 50 years, any age assessment of groundwater requires the

XLVII. No $2-697$ 
prior knowledge of the values of tritium in rainwater when the actual recharge took place. For the relevant mathematical manipulation, these values constitute the "input function"(Mook, 2005).

Tritium is used for dating groundwater, for relatively recent ages up to a past few decades. For the study of dynamics of groundwater systems, in which water has a mean age of over 500 years, a ${ }^{14} \mathrm{C}$ isotope which has a half-life of 5730 years is used instead.

In this study we have not proceeded to the exact determination of the average residence time of water in aquifers because of the lack of adequate number of tritium measurements of both groundwater and seasonal rainwater samples. We limited therefore the usage of tritium values found in groundwater samples, for comparisons reasons only, for the purpose that they could reveal the relative residence time of water in different aquifers spatially differentiated among themselves by the different examined points (areas) within the whole study area.

\section{Results}

The altitude effect of the precipitation on isotopic composition has been determined for the study area, by using data coming from three specific rain gauge stations namely, Thission, Patras, Pendeli of the Global Network of Isotopes in Precipitation (G.N.I.P.). This Network was constructed by the International Atomic Energy Agency (I.A.E.A.) in cooperation with the World Meteorological Organization (W.M.O.). The selection here of these three specific stations (Patras, Thission, Pendeli), out of the whole GNIP network, was based on the fact that they have showed the longest and most complete time series from all the available stations, while at the same time they are located closer to the study area.

Regression analysis between $\delta^{18} \mathrm{O}$ values and altitude values for the three stations gave a linear relationship as shown in figure 2. The $\delta^{18} \mathrm{O}$ values and altitude values of the groundwater sampling points show the same, descending with altitude relationship, with all groundwater sampling points located beneath the GNIP network regression line, which is interpreted that their mean altitude of recharge is most likely to be higher than the actual altitude at the sampling site.

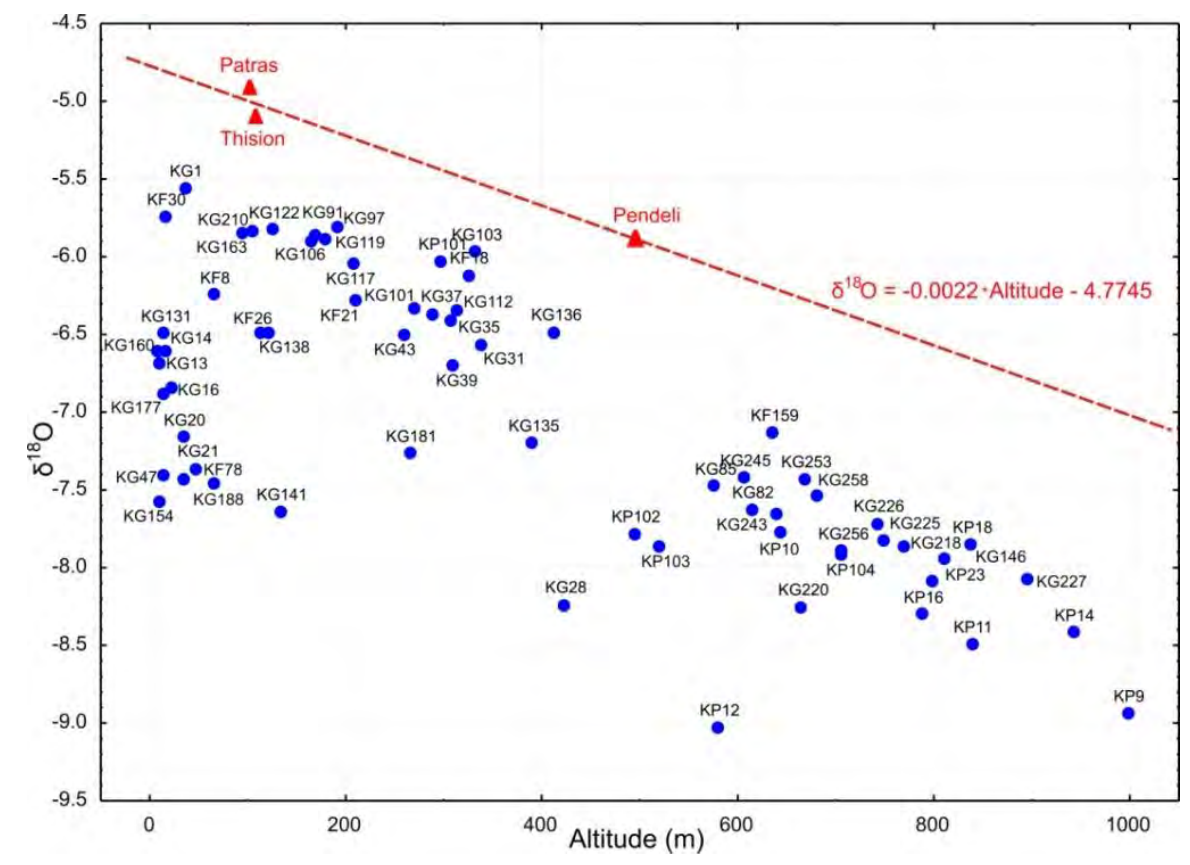

Figure 2 - Diagram of the observed mean $\delta^{18} \mathrm{O}$ values in groundwater versus altitude values of the corresponding sampling points.

$\underline{\text { XLVII. No } 2-698}$ 
The points that are very close to the line show that the mean altitude of the recharge area is almost the same with the elevation of sampling. On the contrary, sample points plotted very far from the line illustrate that they are mainly recharged from much higher altitudes than the one of the sampling site.

If we calculate residuals values for the groundwater sampling points, i.e. the difference between measured values of $\delta^{18} \mathrm{O}$ and estimated values of $\delta^{18} \mathrm{O}$, the latter's being derived from the regression equation shown in figure 2 , we can eventually estimate the spatial distribution of residual values by using the spatial interpolation methods. The result of this procedure is shown in the map of Figure 3.

As it can be seen from this map, Vocha coastal alluvial aquifer has high residual values and seems to be recharging entirely by groundwater coming from higher elevations. This water may be transferred into the aquifer in two ways. Either laterally from adjacent aquifers or by induced recharge coming mostly from the rivers and streams that flow through the alluvial aquifer system and their flow constituted mostly by their base flow. In the first case, ground water in the alluvial aquifer should have longer residence times in the aquifer, and hence relatively high tritium values, whereas in the second case ground water should have a short residence time and hence low values of tritium.

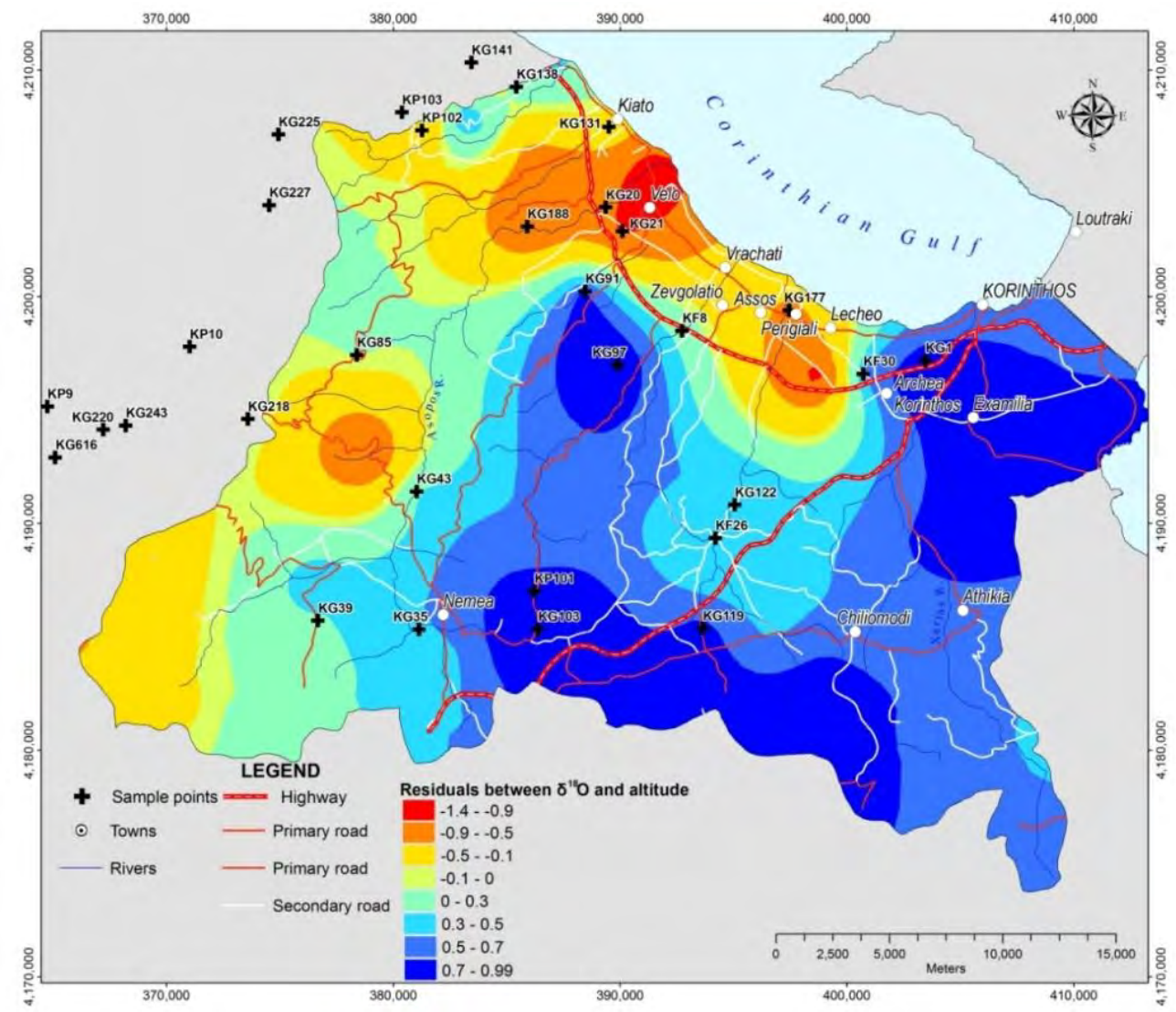

Figure 3 - Residuals between measured and estimated values.

As it can also be seen from the map of Figure 3, the aquifer systems of conglomerates W-NW of Nemea appear to be recharging directly from rainwater falling in the areas where they outcrop or possibly laterally via underground water coming from karst aquifers that outcrop at higher altitudes. The rest of the aquifer systems of the study area appear to be recharging exclusively 
from areas where the geological formations within those areas form aquifers that outcrop with the exception of the carbonate karst aquifers in the SW edge of the study area which appear to be recharging from slightly higher altitudes and from the marl aquifers lying SW of Nemea. (Antonakos, 2012).

As shown in the spatial distribution of tritium map in Figure 4, Sikyon - Velo and Vrahati-Lecheo areas have relatively low rates of tritium, indicating that the groundwater in these areas is recharged inductively by Asopos and Rachiani riverbeds respectively. On the contrary the high tritium values in Krines- Zevgolatio area indicate lateral recharge from the adjacent aquifers of the marine terraces and marls formation.

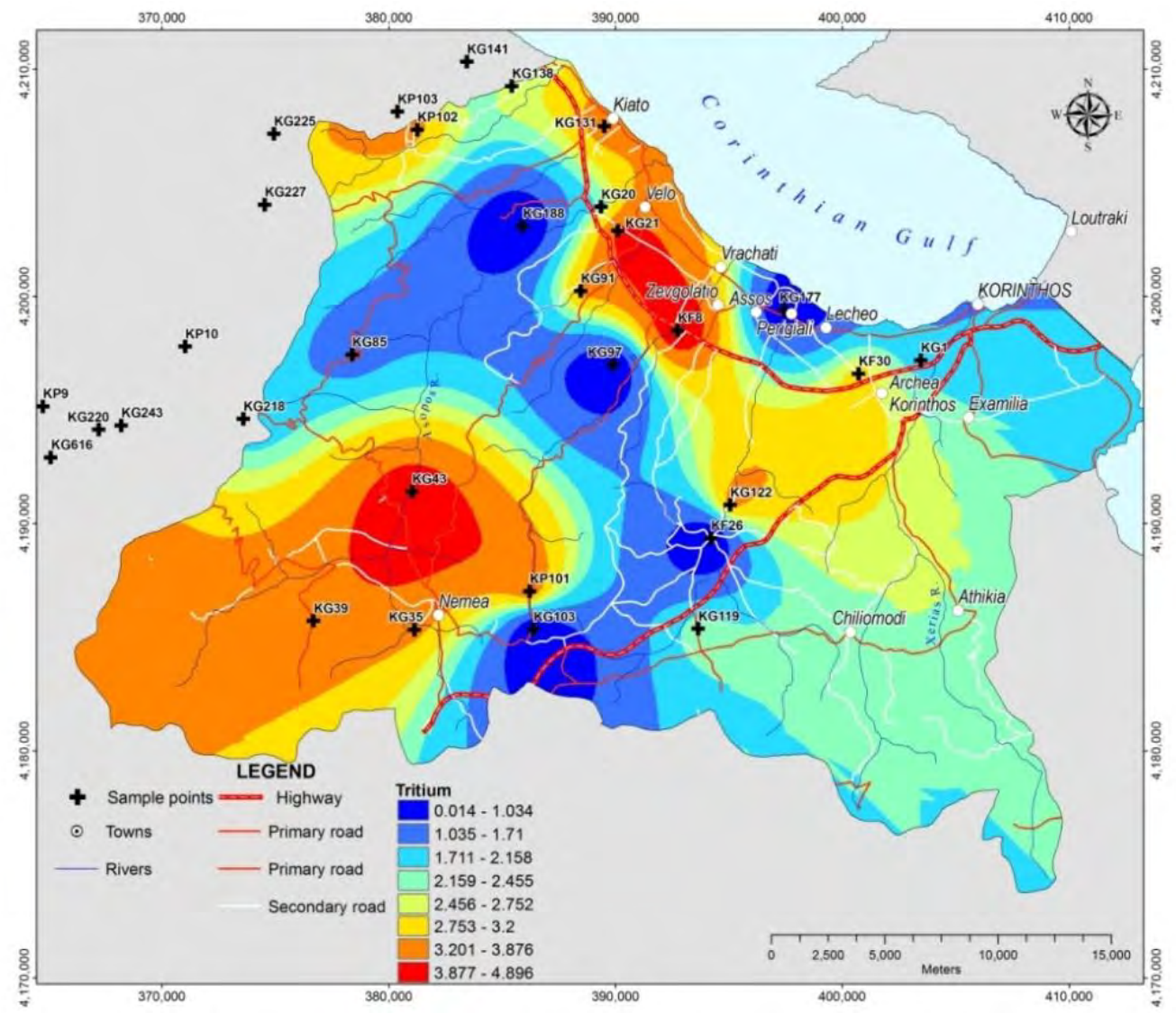

Figure $4-{ }^{3} \mathrm{H}$ spatial distribution map of the study area.

High values of tritium are also observed in the granular aquifer system of Nemea and mostly in the Koutsi area, without being noticing the expected otherwise high residual values between measured and estimated values of $\delta^{18} \mathrm{O}$. In this case, the low observed residual values indicate that the recharge of groundwater comes exclusively from direct infiltration of meteoric water into the groundwater system; hence the high prices of tritium observed, reflect the problematic recharge and discharge of water, totally resulting in the long residence time of waters within the groundwater system of the local aquifer.

\section{Conclusion and Discussion}

Isotopic Hydrology can be a valuable tool for the determination of recharge mechanism of aquifers, particularly in areas of complex geological and hydrogeological structure. In the case of the study area by using $\delta^{18} \mathrm{O}$ and ${ }^{3} \mathrm{H}$ values in groundwater samples and by studying their spatial distribution 
either independently or in comparison, we were able to clarify the recharge mechanism of aquifers and also to determine possible explanations for their groundwater hydrochemical composition.

\section{Acknowledgments}

The authors wish to express their thanks to Dr. Nikolaos Zouridakis, senior research scientist in the Isotope Hydrology Laboratory of Physical Chemistry of NCSR "Demokritos", for the implementation of the isotopic analyses and for his valuable knowledge on isotopic hydrology issues which was kindly transferred to us.

\section{References}

Antonakos A. 2012. Use of Geographic Information Systems (G.I.S.) for Environmental Hydrogeology problems in Corinthian Prefecture, Doctoral Thesis, Patras University Academic Colection, pp. 307. Available online at: http://hdl.handle.net/10889/5773

Antonakos, A., Lambrakis, N., 2007. Development and testing of three hybrid methods for the assessment of aquifer vulnerability, Journal of Hydrology, 333: 288-304.

Christodoulou Th., Leontiadis I.L., Morfis A., Payne B.R. and Tzimourtas S., 1993. Isotope hydrology study of Axios River plain in northern Greece. J. Hydrol., 146: 391-404.

International Atomic Energy Agency (IAEA), 1981. Statistical treatment of environmental isotope data in Precipitation. Tech. Rep., Ser. No. 206, IAEA, Vienna.

Kallergis G. and Leontiadis I.L., 1983. Isotope hydrology study of Kalamos Attikis and Assopos river plain areas in Greece, J. Hydrol., 60: 209-225.

Katsikatsos G. 1992. Geology of Greece. Patras University, O.P.E.B., Pages 451

Kendall C. and Caldwell E. A. 1998. Fundamentals of Isotope Geochemistry, In: C. Kendall and J.J. McDonnell (Eds.), Isotope Tracers in Catchment Hydrology, Elsevier Science, Amsterdam, pp. 51-86.

Leontiadis I.L., Vergis S. and Christodoulou T., 1996. Isotope hydrology study of areas in Eastern Macedonia and Thrace, Northern Greece, Journal of Hydrology 182: 1-17

Matiatos I., Alexopoulos A., and Zouridakis N., 2010. Use of stable isotopes in the determination of the mean altitude of recharge and the investigation of function mechanism of spring waters in Argolis peninsula (Greece). Bulletin of the Geological Society of Greece, 2010 Proceedings of the 12th International Congress.

Mouk W.G. 2005. Introduction to Isotope Hydrology, London, Taylor and Francis Publications, $223 \mathrm{pp}$.

Nikas K. and Antonakos A. 2010. Water Resources of North Peloponnese Water District, with Emphasis on Quality Characteristics and Seawater Intrusion Phenomena, IGME study in compliance with the EU ${ }^{\text {rd }}$ Framework Program. 80 pp, 47 thematic map sheets. 7 separate annexed volumes. IGME Library.

Nikas K., Antonakos A., Kallergis G., and Kounis G. 2010. International Hydrogeological Map of Europe: Sheet D6 "Athina". Bulletin of the Geological Society of Greece, 2010, Proceedings of the 12th International Congress Patras. XLIII, No 4: p. 1821-1830

Nikas K., Antonakos A., Maravegias D. 2008. Study of hydraulic parameters of carbonate aquifers of Gavrovo-Tripolis and Olonos-Pindos isopic zones in Peloponnese, Mineral Wealth, 147: 7-30

Thornthwaite C.W. and Mather J.R. 1955. The water balance. Thornthwaite Ass. Lab., New Jersey. In: Climatology 8 (1), 1-37.

Voudouris K.S., Mavrommatis Th.P. and Antonakos A., 2007. Hydrologic balance estimation using GIS in Korinthia prefecture, Greece Adv. Sci. Res., 1, 1-8, 2007, Available online at: www.adv-sci-res.net/1/1/2007/

Voudouris K., Panagopoulos, A. and Koumantakis J., 2000. Multivariate statistical analysis in the assessment of hydrochemistry of the northern Korinthia Prefecture alluvial aquifer system, Peloponnese, Greece, Natural Resources Research, 9(2), 135-143. 